\title{
Epidemiological evaluation of release of monocyte TNF- $a$ as an exposure and effect marker in pneumonoconiosis: a five year follow up study of coal workers
}

\author{
Roel P F Schins, Paul J A Borm
}

\begin{abstract}
Objectives-To determine (a) reproducibility with previous cross sectional findings, and $(b)$ the predictive value of initial release of tumour necrosis factor-a (TNF-a) towards later progression of coalworkers' pneumoconiosis (CWP). Methods-Release of monocyte TNF-a after in vitro stimulation with coal mine dust, silica, and endotoxin was measured in 104 retired miners and was related to stage of CWP (chest radiograph) and cumulative exposure. A subgroup of 46 miners was screened by high resolution computed tomography (HRCT). Prospective analysis of TNF-a (40 out of 104 miners involved in the previous TNF-a study) was done by relating initial TNF-a to five year progression of CWP measured by comparison of paired chest radiographs.

Results-As observed previously, dust stimulated release of TNF-a was increased in miners, especially in the early stages of pneumoconiosis. Cumulative exposure was related to pneumoconiotic stage but not to release of TNF-a. This excluded TNF- $a$ as an exposure marker. Initial concentrations (1987) of TNF- $a$ were related to later progression of CWP. Miners who showed abnormally high dust stimulated release of TNF-a had an increased risk of progression in CWP (relative risk $8 \cdot 1$ ).

Conclusions-These results show $(a)$ the significant involvement of TNF- $a$ in pneumoconiosis in humans induced by coal dust and (b) that this routine test possibly constitutes a powerful tool to estimate individual prognosis of pneumoconiotic disease, even after the end of occupational exposure.
\end{abstract}

Department of Health

Risk Analysis and

Toxicology, University

of Limburg,

Maastricht, The

Netherlands

R P F Schins

P J A Borm

Correspondence to:

Roel P F Schins MSc

Department of Health Risk

Analysis and Toxicology

Anilysis and oxicology,

Box $6166200 \mathrm{MD}$

Netherlands.

Accepted 7 March 1995 cell types, in which alveolar macrophages, lung epithelium, fibroblasts, type II cells, polymorphonuclear leucocytes, and many other cells are involved. ${ }^{12}$ These cells are
Keywords: tumour necrosis factor- $a$; coal workers'

Pulmonary fibrosis should be looked upon as known to produce various factors (reactive oxygen species, cytokines, enzymes, etc) that are thought to be crucial mediators of the hallmarks of pulmonary fibrosis: excessive fibroblast proliferation and collagen deposition..$^{23}$ Mediators that have been put forward, mostly from animal studies, are: platelet derived growth factor- $\beta$ (PDGF- $\beta$ ), tumour necrosis factor- $\alpha$ (TNF- $\alpha$ ), Interleukin- $1 \beta$ and Interleukin-6 (IL-1 $\beta$, IL-6), and prostaglandin- $\mathrm{E}_{2}\left(\mathrm{PGE}_{2}\right)$ in asbestosis, ${ }^{45}$ or TNF- $a$, IL-1, and the macrophage inflammatory proteins $1 a$ and 2 (MIP-1 $a$, MIP-2) in silicosis. ${ }^{6-9}$ The potential of many of these cell mediators as markers of exposure, disease susceptibility, or effects has been raised many times, but studies on the relations between exposure, disease, and cytokine release in occupationally or environmentally exposed subjects are scarce.

In 1987 several case-control studies among coal miners were performed in our laboratory to look for a marker to explain disease among exposed miners with and without coal workers' pneumoconiosis (CWP), The serum concentration of procollagen type III peptide (PIIIP) was measured to assess fibrotic activity $v$ pneumoconiotic stage. ${ }^{10}$ Another study focused on the relation between CWP and antioxidant expression. ${ }^{11}$ The in vitro secretion of TNF- $a$ by peripheral blood monocytes $^{12}$ of healthy miners and miners with coal miners' pneumoconiosis, ${ }^{12}$ matched on age and underground working years, showed that the release of TNF- $a$ in monocytes could be stimulated in vitro by coal mine dust, and that (healthy) coal miners had a higher release of monocyte TNF- $a$ upon in vitro stimulation than did controls who were not exposed to dust. Moreover, a decreasing trend in release of TNF- $a$ was seen along with the clinical progression of CWP possibly as a positive feedback mechanism to prevent concentration of fibrosis, and in healthy miners $(0 / 0)$ and miners with early stages of CWP (0/1) a large variation in the TNF- $a$ released was found. We then suggested that people who showed values largely exceeding the normal range of the controls who were not exposed to dust, were at risk of development of CWP and concluded that "definitive proof for the role of mononuclear phagocyte-derived TNF in the pathogenesis of CWP and other fibrotic lung diseases has to originate from laboratory animal studies and prospective epidemiological surveys among those at risk" ${ }^{12}$ Several years 
ago, Piguet and coworkers showed the crucial role of TNF- $a$ in fibrosis induced by silica with a mouse in vivo model. Since then other studies have firmly established the importance of TNF- $a$ in lung fibrosis induced by silica. ${ }^{7813}$ Also in vitro studies have emphasised the involvement of TNF- $a$ in the complex cytokine network of lung tissue. ${ }^{1-5} 1415$ Lasalle and coworkers reported an increased spontaneous release of TNF- $\alpha$ by alveolar macrophages of active healthy coal miners and miners with CWP compared with controls. ${ }^{16}$ The importance of these findings for the prevention of lung fibrosis induced by mineral dust remains an open question. In 1992 all miners involved in our cross sectional studies were recruited for a five year follow up to investigate whether our previous cross sectional findings on release of TNF- $a$ in subjects exposed to dust and disease stage of CWP could be validated, and to determine the relative risk of development of CWP for coal miners who showed high in vitro release of TNF- $a$.

\section{Methods}

STUDY GROUP

Miners ( $n=156$, fig 1 ) from the Belgian coal mining industry "Kempense Steenkoolmijnen" involved in previous studies in $1987^{10-12}$ were asked to participate in the follow up study that included a chest radiograph, several lung function tests, medical and exposure history, and the blood variables TNF- $a$, PIIIP, and red blood cell antioxidant enzymes. Chest radiographs taken in 1987 and in 1992 were scored according to the International Labour Office (ILO) classification rules ${ }^{17}$ by an experienced panel of three physicians. A subgroup of 46 miners was screened by high resolution computed tomography (HRCT) by invited participation. Percentages of cases and control miners in the HRCT subgroup (13 $v 23$ ) were equal to those of the large cohort (28 and 76), and none of the variables; age,

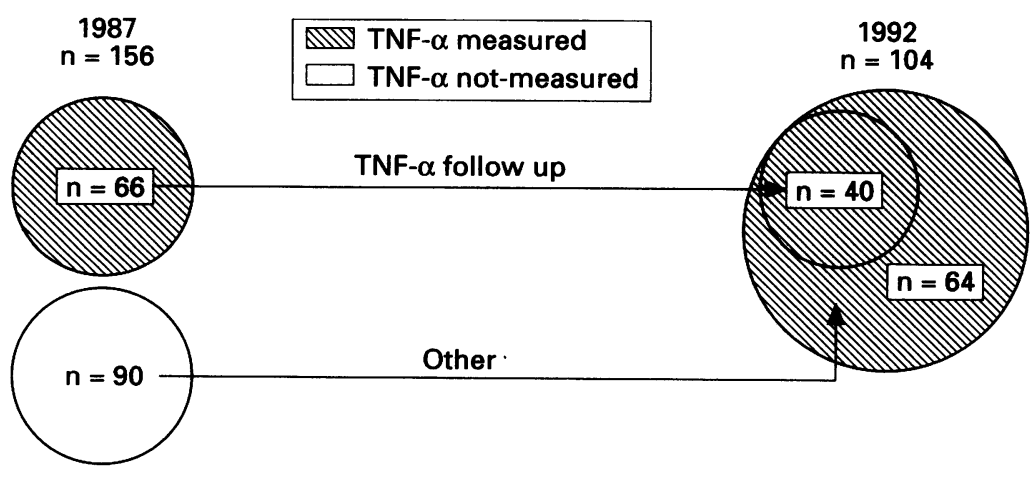

Figure 1 Construction of the follow up study of retired coal miners previously (1987) involved in cross sectional studies on the role of TNF-a $(n=66)$ or antioxidants $(n=90)$ in coal workers pneumoconiosis. Data interpretation is done either by comparison of the TNF-a follow up group $(n=40)$ (longitudinal analysis) or of the total 1992 cohort $(n=104)$ with the TNF-a group in $1987(n=66)$ (cross sectional analysis). Chest radiographs were taken for all miners in $1987(n=156)$, and for all miners involved in $1992(n=104)$, allowing 104 paired chest radiograph comparisons (determination of five year progression of CWP). From the 1992 cohort $(n=104), 46$ miners were screened by high resolution computed tomography by invited participation. smoking habits, or exposure in the subgroup were different from the large cohort $(n=$ 104). A control group of 44 age matched men participated in the study on a voluntary basis. Exclusion criteria for the controls not exposed to dust were: working for more than one year in an occupational setting with chronic dust exposure (mining, cement works, ceramic industry, bakery, etc) and one or more of: asthma, (chronic) bronchitis, and other chronic diseases of lung, liver, and kidney. Based on these criteria, 29 controls were included in the statistical analysis.

\section{TNF- $\alpha$ ASSAY}

Release of monocyte TNF- $a$ was measured as described previously. ${ }^{12}$ Briefly, blood $(3 \times 10 \mathrm{ml})$ was sampled and left overnight in tubes with EDTA at room temperature. White blood cells were isolated by buoyant density centrifugation (Lymphoprep-Nycomed), adjusted to concentrations of $0.5 \times 107 \mathrm{cells} / \mathrm{ml}$, and seeded $(0.5 \mathrm{ml})$ to tissue culture dishes (Costar TC-24) to allow adherence (repetitive incubation, agitation, and washing). Adherent monocytes were stimulated with coalmine dust $(5 \mathrm{mg} / \mathrm{ml})$, silica particles $(0.5 \mathrm{mg} / \mathrm{ml})$, or Escherichia coli 0111B4 LPS endotoxin (3 and $1000 \mathrm{ng} / \mathrm{ml}$ ). Silica and endotoxin were obtained from Sigma (St Louis, USA); the coal mine dust (sampled from a coal pit) was obtained from the same batch as used previously. ${ }^{12}$ Each person's baseline release of TNF- $a$ was measured without addition of any in vitro stimulant. After 18 hours of incubation $\left(37^{\circ} \mathrm{C}, \mathrm{CO}_{2}\right)$ the cell free supernatants were stored at $-30^{\circ} \mathrm{C}$ until analysis by a sandwich ELISA specific for TNF- $a$ as described previously. ${ }^{12} 18$

\section{QUESTIONNAIRE}

An extensive questionnaire was sent to all participants in which medical complaints, medical history, smoking habits, and medication were asked for. Answers were all verified during personal interviews at the time of medical screening and by comparison with questionnaires from the data records of our preceding studies. Amount of smoking was expressed as: packets of cigarettes/week $\times$ years (packyears) smoked. One packet was considered to consist of 25 cigarettes; the smoking of one cigar to be equivalent to three cigarettes; and $50 \mathrm{~g}$ (pipe) tobacco to be equivalent to $75 \mathrm{cig}$ arettes. Furthermore all subjects were subdivided into current, former, and never smokers.

Subjects were classified for medication and medical history based on the presence or absence of any medication during three weeks before blood sampling. Disease was determined in two ways; the presence or absence of any medical complaint for at least three days, and of specific disease of the lung, kidney, liver, or any other chronic disease for at least three years before blood sampling.

\section{EXPOSURE}

Much emphasis was put on a good estimation of exposure and several variables were used: 
(a) time worked underground, (b) time since first occupational exposure, $(c)$ time since last occupational exposure, $(d)$ cumulative exposure to respirable coal dust and quartz.

Years exposed, first exposure, and last exposure Years exposed, time since first exposure, and time elapsed since last occupational exposure were determined from the medical file and a personal interview at follow up. Exposure years were determined from the complete job history obtained from each subject and defined as the total number of years in which a subject worked underground in a coal mine. Long term absenteeism - for example, for disease or through special leave-as well as interim job changes were taken into account. Years since first exposure were defined as the interval between the year in which a miner started working underground and the time of our study. Time from last exposure was the interval between retirement and our follow up in months.

\section{Calculation of cumulative dust exposure}

Occupation history, gathered from the medical file and verified by a personal interview, was used to calculate exposure for all periods worked at and out of the coalfaces. The cumulative dust exposure was calculated by summation of the products of the yearly mean dust concentrations for the colliery where the miner was appointed with the average time worked underground during that year.

The formula was:

$$
E_{x}=\sum_{i=1}^{n}\left(C_{i} \cdot T_{x}\right)\left(g h / m^{3}\right)
$$

where $E_{x}=$ cumulative dust exposure $\left(\mathrm{gh} / \mathrm{m}^{3}\right)$ of miner $\mathrm{x} ; \mathrm{C}_{\mathrm{i}}=$ mean dust concentration $\left(\mathrm{g} / \mathrm{m}^{3}\right)$ in year $\mathrm{i} ; \mathrm{T}_{\mathrm{x}}=$ time worked underground $(\mathrm{h})$ by miner $\mathrm{x}$; $\mathrm{n}=$ years of employment.

The resulting individual exposure is expressed in $\mathrm{gh} / \mathrm{m}^{3}$ of sampled air. The yearly mean dust concentrations $\left(C_{i}\right)$ were derived from dust measurements regularly made to check compliance with exposure limits in every coal face of the colliery. Since 1965 these measurements have been carried out with a STASER sampler (jointly developed by a Belgian manufacturer and the Dutch State Mines) at fixed points, $15 \mathrm{~m}$ from the face line, in the return end gate. The concentrations before 1965 have been estimated on the basis of preliminary studies carried out in preparation for the implementation of dust regulations. The total dust concentrations have been converted into "respirable" dust concentrations by the formula:

$$
\mathrm{rd}=1 \cdot 1 \sqrt{\mathrm{td}}\left(\mathrm{gh} / \mathrm{m}^{3}\right)
$$

where $\quad \mathrm{rd}=$ respirable dust concentration $\left(\mathrm{g} / \mathrm{m}^{3}\right) ; \mathrm{td}=$ total dust concentration $\left(\mathrm{g} / \mathrm{m}^{3}\right)$, as measured.

This empirical relation (equation 2) was derived from experimental side by side instrument comparisons conducted in 1984-5 with the French CPM3 instrument and the STASER sampler under various mining conditions in the Belgian coal mines (144 paired measurements). The time worked underground was estimated for each subject assuming that on average 1000 hours a year were worked underground: six hours at work a shift (allowance being made for travelling time) $\times 220$ shifts a year $\times(100-25) / 100$ (where $25 \%$ is taken as the rate of absenteeism). The exposure outside the coal face was estimated on the basis of professional judgement of the "dustiness" of the occupation and the knowledge of normal respirable dust levels in that job (non-mechanised and mechanised headings, stone drivages, etc). The cumulative quartz exposure $\left(\mathrm{mgh} / \mathrm{m}^{3}\right)$ has been estimated, based on the average quartz content of Belgian coal faces $(5 \%)$ and stone drivage dust (10\%).

\section{RADIOGRAPHY}

\section{Protocol and classification}

Chest radiographs $(46 \times 46 \mathrm{~cm})$ were taken posterior to anterior at maximal inspiration $(1.5 \mathrm{~m}$ distance, $70 \mathrm{kV})$ and scored according to the ILO criteria. ${ }^{17}$ Scoring was done in plenary sessions where consensus had to be reached based on individual scores. The reading panel consisted of three occupational physicians of whom two were seeing more than 3000 chest radiographs a year, and one is a trained reader but had not been active as such for the past three years. Two readers in our follow up study had been involved with the original study. Standard ILO chest radiographs were used as reference to classification. Based on the ILO scores the cohort was subdivided into five groups: ILO classification $0 / 0$ (group 0), class $0 / 1$ (group 1), classes $1 / 0,1 / 1$, and $1 / 2$ (group 2), classes $2 / 1,2 / 2$, and $2 / 3$ (group 3), classes $3 / 2$ and $3 / 3$ (group 4), and finally $3 /+$ and subjects with progressive massive fibrosis (group 5). Furthermore miners were grouped as either "healthy coal workers" with ILO classification of $0 / 0$ (group 0 only) or as miners with evidence for CWP with ILO classification of $\geqslant 0 / 1$ (groups 1 to 5 ). Five year changes in pneumoconiosis were determined by comparison of each man's chest radiographs of 1987 and 1992 . All radiographs were scored in a randomised blind reading session, as well as in pairs; the paired scoring session was used as definitive evidence of progression as this direct comparison allows the best validation of TNF- $\alpha$ as a marker of five year changes in pneumoconiosis.

\section{High resolution computed tomography}

The HRCT scans were made (Somaton plus, Siemens, Erlangen, Germany) and visually scored by two radiologists as described elsewhere $^{19}$ in a subgroup of 46 miners. Briefly, four HRCT slices, two in the upper lobes ( 3 and $5 \mathrm{~cm}$ above the carina) and two in the lower lobes ( 3 and $5 \mathrm{~cm}$ below the carina) were obtained at full inspiration in a supine position, and scored independently by two thoracic radiologists without knowledge of 
clinical findings. Each slice was visually assessed for the presence of non-calcified parenchymal opacities with almost the same basic principles as the ILO system for grading pulmonary disease on chest radiographs. The profusion score was converted to a linear scale that ranged from zero to 10 as follows: $0 / 0=$ $0,0 / 1=1,1 / 0=2,1 / 1=3,1 / 2=4,2 / 1=5$, $2 / 2=6,2 / 3=7,3 / 2=8,3 / 3=9$ and $3 /+=$ 10. ${ }^{19} 20$ The score of the eight lung fields was summed up and a total score was calculated. The mean score of both observers (correlation $0.86, P<0.001$ ) was calculated for the purpose of this study. Our attention was mainly focused on the relation between TNF- $a$ and HRCT lesions in a group of 35 miners without the classic diagnostic evidence of CWP (ILO $\leqslant 0 / 1$ ).

DATA EVALUATION AND STATISTICAL ANALYSIS Figure 1 shows the composition of the study group. Exploratory analysis was performed on the 1992 cross sectional data, to study the confounding effects of age, smoking, medication, and variables of exposure. Reproducibility with cross sectional data of 1987 was then evaluated by unpaired statistical analysis of data obtained in $1987^{12} v$ data obtained in 1992 and by cross sectional analysis of 1992 data as previously described for the 1987 cross sectional data. ${ }^{12}$ Longitudinal study analysis was performed by paired statistical analysis of 1987 and 1992 data and predictive values of variables of 1987 (prospective analysis) or 1992 (retrospective analysis) were related to five year changes in radiological severity of CWP.

Correlations between release of TNF- $a$ and exposure, age, and smoking were evaluated by multiple linear regression. Differences between miners with or without CWP and non-exposed controls, and effects of medication, medical history, and smoking were tested by the Kruskall Wallis test. Trend between pneumoconiotic stage (chest radiographs, HRCT) and TNF-a, exposure, or other variables was analysed by Spearman's rank correlation. For this purpose, profusion scores were converted to a scale from 0 to 11 for chest radiograph classification and 0 to 80 for HRCT as already indicated. Positive pre-

Table 1 Group characteristics of the study cohort in $1992(n=133)$

\begin{tabular}{lccc}
\hline & $\begin{array}{l}\text { Controls not } \\
\text { exposed to dust } \\
(n=29)\end{array}$ & $\begin{array}{l}\text { Controls healthy } \\
\text { miners } \\
(n=76)\end{array}$ & $\begin{array}{l}\text { Miners } \\
\text { with CWPY } \\
(n=28)\end{array}$ \\
\hline Age (y) & $50 \cdot 3(1 \cdot 0)^{\star}$ & $47 \cdot 7(0 \cdot 6)$ & $49 \cdot 9(1 \cdot 1)$ \\
Smoking (pack-y) & $115(20)$ & $111(12)$ & $150(24)$ \\
Smoking (yes/no) & $16 / 13$ & $28 / 48$ & $14 / 14$ \\
Smoking (ever/never) & $22 / 7$ & $62 / 14$ & $23 / 5$ \\
Medication (yes/no) & $8 / 21$ & $20 / 56$ & $7 / 21$ \\
Cumulative exposure: & - & $91 \cdot 1(6 \cdot 4)$ & $130 \cdot 9(9 \cdot 3)^{\star \star}$ \\
$\quad$ dust (gh/m $\left./ \mathrm{m}^{3}\right)$ & - & $4798(306)$ & $6751(461)^{\star \star}$ \\
quartz $\left(\mathrm{mgh}^{3}\right)$ & - & $22 \cdot 2(0 \cdot 4)$ & $25 \cdot 0(0 \cdot 9)^{\star \star}$ \\
Time underground (y) & - & $28 \cdot 9(0 \cdot 6)$ & $30 \cdot 7(1 \cdot 0)$ \\
Time since first exposure (y) & - & $46 \cdot 3(2 \cdot 1)$ & $53 \cdot 9(2 \cdot 1)$ \\
Time retired (months) & & &
\end{tabular}

${ }^{\star} \mathrm{P}<0.05 ;{ }^{\star \star} \mathrm{P}<0.01$ (Mann-Whitney).

Values are mean (SEM).

†Proportion of smokers/former smokers/never smokers in the ILD profusion categories was: $4 / 2 / 1(0 / 1) ; 1 / 2 / 2(1 / 0,1 / 1,1 / 2) ; 3 / 2 / 2(2 / 1,2 / 2,2 / 3) ; 4 / 2 / 0(3 / 2,3 / 3) ;$ and $2 / 1 / 0(3 /+$ progressive massive fibrosis). dictive value of five year changes in chest radiograph, sensitivity, and specificity of initial release of TNF- $a$ were determined. The relative risk of progression of CWP based on 1987 TNF- $a$ data was determined with a cut off point of 2 SDs above the mean release of TNF- $a$ measured in the non-exposed control group of $1987^{12}$; similarly, the odds ratio (OR) of cumulative dust exposure with progression of CWP was determined retrospectively, with the mean cumulative exposure of the 1992 cohort as a cut off point. Also, to determine the significance of our findings at various cut off points, receiver operating characteristic (ROC) curves were calculated. ${ }^{21}{ }^{22}$ Statistical evaluations were made with version 6.0 of STATGRAPHICS (Manugistics, Rockville, MD).

\section{Results}

ANALYSIS OF EXPLORATORY DATA

Age, smoking, medication, and exposure

Table 1 shows group characteristics of the total study cohort of 1992. The average age of the control group not exposed to dust was significantly higher than the control miners. No correlation was found between age and release of TNF- $a$ in any of the groups (table 2). Smoking habits did not differ among the three groups (table 1), but the release of monocyte TNF- $a$ upon stimulation with coal dust was significantly inversely related to pack-years in miners ( $n=104$, table 2 ). The dust stimulated release of TNF- $a$ was significantly lower in ever smokers $(1.68 \mathrm{ng} / \mathrm{ml}, \mathrm{n}=61) v$ never smokers $(2.90 \mathrm{ng} / \mathrm{ml}, \mathrm{n}=15)$ (ANOVA, $\mathrm{P}<$ 0.01 ) but not significantly different between active smokers $(n=27)$ and non-smokers $(n=49)$. Furthermore, smoking was related to release of TNF- $a$ upon stimulation with coal dust and low concentration of endotoxin ( $3 \mathrm{ng} / \mathrm{ml}$ ) in miners without CWP, and to high concentration of endotoxin $(1000 \mathrm{ng} / \mathrm{ml})$ in the controls not exposed to dust. In the controls exposed to dust the average release of TNF- $\alpha$ upon stimulation with $1000 \mathrm{ng} / \mathrm{ml}$ of endotoxin was significantly different for active smokers $(1.63 \mathrm{ng} / \mathrm{ml}, \mathrm{n}=16) v$ non-smokers ( $3.16 \mathrm{ng} / \mathrm{ml}, \mathrm{n}=13$ ), and for (ever) smokers $(1.85 \mathrm{ng} / \mathrm{ml}, \mathrm{n}=22) v$ never smokers $(3.76$ $\mathrm{ng} / \mathrm{ml}, \mathrm{n}=7$; ANOVA, $\mathrm{P}<0.05)$. Differences in release of TNF- $\alpha$ with respect to medication were not found in any group.

Miners with CWP had significantly higher cumulative exposure and underground working years than the control miners (table 1). No significant relation was found between any of the exposure variables and release of TNF- $a$ (table 2).

REPRODUCIBILITY OF CROSS SECTIONAL DATA Reproducibility of TNF-a data

Figure 2 shows the release of monocyte TNF- $\alpha$ for both cross sectional studies in 1987 and 1992, for the controls not exposed to dust, the control miners, and miners with pneumoconiosis. Unpaired $t$ tests of all miners involved in the original study and in the entire follow up group showed that both the 
Table 2 Linear correlations between TNF- $a$ and exposure, age, and smoking

\begin{tabular}{|c|c|c|c|c|c|c|}
\hline \multirow[b]{2}{*}{$\begin{array}{l}\text { ILO } \\
\text { classification }\end{array}$} & \multirow[b]{2}{*}{$n$} & \multicolumn{5}{|c|}{ Release of TNF-a by stimulation with } \\
\hline & & Spontaneous & $\begin{array}{l}\text { Endotoxin } \\
3 \mathrm{ng} / \mathrm{ml}\end{array}$ & $\begin{array}{l}\text { Endotoxin } \\
1000 \mathrm{ng} / \mathrm{ml}\end{array}$ & $\begin{array}{l}\text { Coal mine dust } \\
5 \mathrm{mg} / \mathrm{ml}\end{array}$ & $\begin{array}{l}\text { Silica } \\
0.5 \mathrm{mg} / \mathrm{ml}\end{array}$ \\
\hline $\begin{array}{c}\text { Cumulative } \\
0 / 0 \\
\geqslant 0 / 1 \\
\text { Total }\end{array}$ & $\begin{array}{c}\left.\mathrm{h} / \mathrm{m}^{3}\right): \\
(76) \\
(28) \\
(104)\end{array}$ & $\begin{array}{r}0.01 \\
-0.28 \\
-0.06\end{array}$ & $\begin{array}{r}0.17 \\
-0 \cdot 10 \\
0.08\end{array}$ & $\begin{array}{r}0.02 \\
-0.02 \\
0.01\end{array}$ & $\begin{array}{r}0.00 \\
-0.20 \\
-0.04\end{array}$ & $\begin{array}{r}0.10 \\
-0.06 \\
0.03\end{array}$ \\
\hline $\begin{array}{c}\text { Cumulative } \\
0 / 0 \\
\geqslant 0 / 1 \\
\text { Total }\end{array}$ & $\begin{array}{c}(\mathrm{mgh} / \mathrm{m} \\
(76) \\
(28) \\
(104)\end{array}$ & $\begin{array}{r}0.03 \\
-0.33 \\
-0.06\end{array}$ & $\begin{array}{r}0.19 \\
-0.05 \\
0.11\end{array}$ & $\begin{array}{l}0.02 \\
0.06 \\
0.03\end{array}$ & $\begin{array}{r}0.05 \\
-0.23 \\
-0.02\end{array}$ & $\begin{array}{r}0.11 \\
-0.10 \\
0.03\end{array}$ \\
\hline $\begin{array}{c}\text { Time underg } \\
0 / 0 \\
\geqslant 0 / 1 \\
\text { Total }\end{array}$ & $\begin{array}{l}(y): \\
(76) \\
(28) \\
(104)\end{array}$ & $\begin{array}{r}-0.05 \\
0.05 \\
-0.04\end{array}$ & $\begin{array}{l}0.12 \\
0.16 \\
0.12\end{array}$ & $\begin{array}{r}-0.03 \\
0.30 \\
0.08\end{array}$ & $\begin{array}{r}-0.02 \\
0.10 \\
0.02\end{array}$ & $\begin{array}{l}0.00 \\
0.16 \\
0.05\end{array}$ \\
\hline $\begin{array}{c}\text { Time since } \mathrm{f} \\
0 / 0 \\
\geqslant 0 / 1 \\
\text { Total }\end{array}$ & $\begin{array}{c}\text { posure }( \\
(76) \\
(28) \\
(104)\end{array}$ & $\begin{array}{r}-0.22 \\
0.08 \\
-0.15\end{array}$ & $\begin{array}{r}0.01 \\
-0.01 \\
0.00\end{array}$ & $\begin{array}{r}-0.06 \\
0.16 \\
0.01\end{array}$ & $\begin{array}{l}-0 \cdot 17 \\
-0.02 \\
-0.12\end{array}$ & $\begin{array}{r}-0 \cdot 18 \\
0.00 \\
-0 \cdot 10\end{array}$ \\
\hline $\begin{array}{l}\text { Age }(y): \\
0 / 0 \\
\geqslant 0 / 1 \\
\text { Total } \\
\text { Control† }\end{array}$ & $\begin{array}{r}(76) \\
(28) \\
(104) \\
(29)\end{array}$ & $\begin{array}{r}-0.02 \\
0.05 \\
0.05 \\
0.13\end{array}$ & $\begin{array}{r}0.11 \\
0.14 \\
0.07 \\
-0.09\end{array}$ & $\begin{array}{r}-0.05 \\
0.09 \\
-0.03 \\
0.07\end{array}$ & $\begin{array}{l}0.00 \\
0.16 \\
0.03 \\
0.09\end{array}$ & $\begin{array}{r}0.07 \\
0.29 \\
0.05 \\
-0.20\end{array}$ \\
\hline $\begin{array}{l}\text { Smoking (pa } \\
0 / 0 \\
\geqslant 0 / 1 \\
\text { Total } \\
\text { Controlt }\end{array}$ & $\begin{array}{r}(76) \\
(28) \\
(104) \\
(29)\end{array}$ & $\begin{array}{r}0.16 \\
-0.04 \\
0.09 \\
-0.15\end{array}$ & $\begin{array}{l}-0.24^{\star} \\
0.00 \\
-0.16 \\
-0.25\end{array}$ & $\begin{array}{l}-0.12 \\
0.03 \\
-0.07 \\
-0.46^{\star}\end{array}$ & $\begin{array}{l}-0 \cdot 27^{\star} \\
-0.27 \\
-0.26^{\star \star} \\
-0 \cdot 20\end{array}$ & $\begin{array}{l}-0.14 \\
-0.07 \\
-0.11 \\
-0.09\end{array}$ \\
\hline
\end{tabular}

$r=$ correlation coefficient significant at ${ }^{\star} \mathrm{P}=0.05$ or ${ }^{\star \star P}=0.01$.

† Not exposed to dust.

spontaneous release of TNF- $a$ and the release of TNF- $a$ upon stimulation with a low concentration of endotoxin $(3 \mathrm{ng} / \mathrm{ml})$ in 1992 ( $n=104$ ) were both significantly lower than in 1987 ( $n=66)$; conversely, release of TNF$a$ stimulated by coal mine dust was significantly higher in 1992 than in the 1987 study $(P<0.05)$. Spontaneous release of TNF- $a$ and release of TNF- $a$ upon stimulation with a low concentration of endotoxin were signifi- cantly reduced in the healthy coal miners of $1992(\mathrm{n}=76) v 1987(\mathrm{n}=39)$ as well as in the miners with CWP of $1992(\mathrm{n}=28) v$ $1987(n=27)$. On the other hand, stimulation with coal mine dust released significantly higher concentrations of TNF- $a$ in the healthy miners of $1992 v 1987$, but not in the miners with CWP of $1992 v 1987$. Release of TNF- $a$ upon dust stimulation was also significantly increased in the controls not exposed to dust
Figure 2 Mean release of TNF-a from blood monocytes in 1987 and 1992. Data were obtained from 12 and 29 (1987v

1992) control subjects not exposed to dust, from 39 and 76 control miners exposed to dust and from 27 and 28 miners exposed to dust who had coal workers' pneumoconiosis. All values are means (SEM) and are expressed in $\mathrm{ng} / \mathrm{ml}$. Testing for significance was with the Mann-Whitney U test; the asterisks indicate significant differences between 1987 and 1992 data.

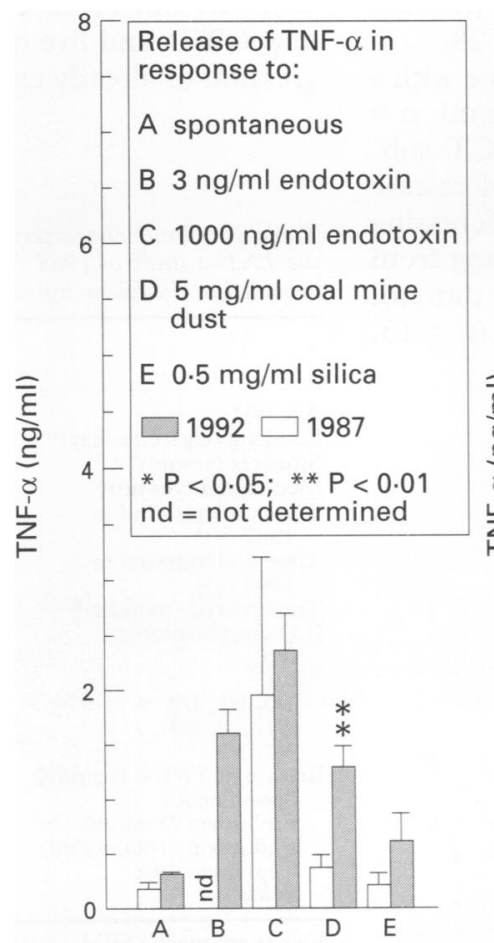

Control (not exposed to dust)

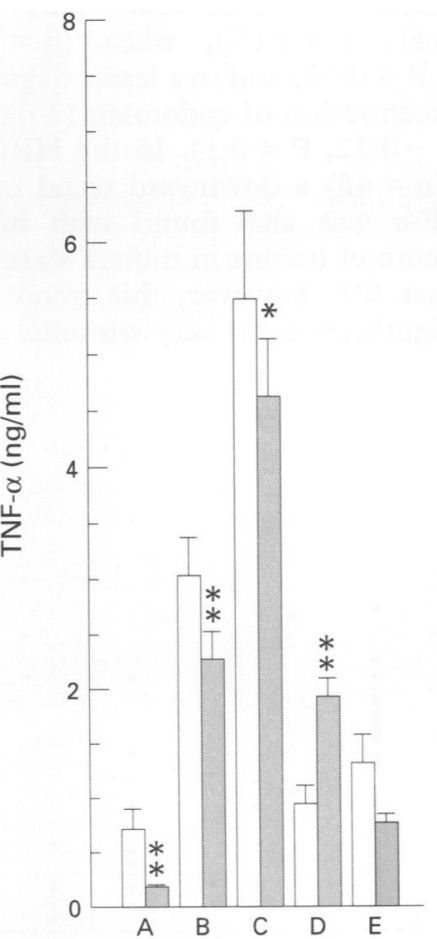

Control (healthy miners)

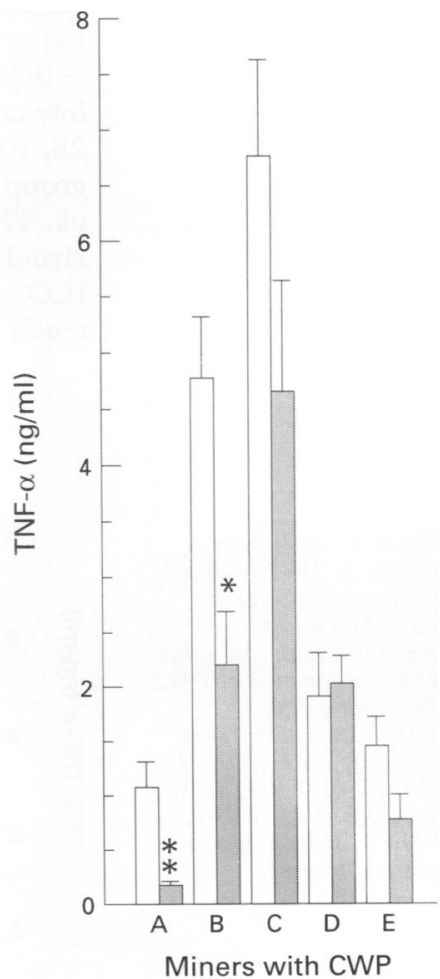


in $1992(\mathrm{n}=29) v$ the control group of 1987 $(n=12)$. Other (unpaired) differences were not found.

Despite these differences in absolute values between the studies, the 1992 cross sectional comparison of release of TNF- $a$ between controls not exposed to dust, control miners, and miners with CWP confirmed our previous findings (fig 2). Again, release of TNF- $a$ in the controls not exposed to dust was significantly lower than in the control miners upon stimulation with a high concentration of endotoxin $(1000 \mathrm{ng} / \mathrm{ml})$ and stimulation with silica. At present also release of TNF- $a$ in the controls not exposed to dust was significantly lower than in the control miners and miners with CWP upon stimulation with coal mine dust (Mann-Whitney $U$ test $P<0.05$ ). Contrary to previous findings, however, none of the stimuli resulted in significant differences in release of TNF- $a$ between miners with or without CWP; moreover the spontaneous release of TNF- $a$ was significantly higher in controls not exposed to dust $v$ both miners' groups (Mann-Whitney, $\mathrm{P}<0.01$ ).

\section{TNF- $a$ and profusion score}

Figure 3 shows the individual TNF- $a$ data for the total follow up group $(n=104)$ upon stimulation with coal mine dust as a function of profusion score. As previously, ${ }^{12}$ a large variation in response to TNF- $a$ upon stimulation with coal mine dust was found in healthy miners. In miners in the early stages of CWP, release of TNF- $a$ was significantly increased and a decrease in release of TNF- $a$ was found along with the increasing stage of CWP that seems to continue in progressive massive fibrosis. Spearman rank correlation tests showed a significant downward trend in release of TNF- $a$ with increasing profusion score starting from the ILO score $0 / 1$, upon stimulation with coal mine dust $(n=28$, $r=-0.41, \quad \mathrm{P}<0.05)$, silica $(\mathrm{n}=28, \quad r=$ $-0.39, P<0.05)$ and to a lesser degree with a low concentration of endotoxin $(3 \mathrm{ng} / \mathrm{ml}, \mathrm{n}=$ 28, $r=-0.32, \mathrm{P}<0.1)$. In the HRCT subgroup $(n=46)$ a downward trend of release of TNF- $a$ was also found with increasing visual score of lesions in miners starting from ILO class $0 / 1$; however, this trend did not reach significance for any stimulus $(n=13$,

Figure 3 Release of TNF-a in 1992 in $\mathrm{ng} / \mathrm{ml}$ of blood monocytes of individual miners stimulated with coal mine dust as a function of 1992 chest radiograph classification. Profusion categories are $0(0 / 0), 1$ $(0 / 1), 2(1 / 0,1 / 1,1 / 2), 3$ $(2 / 1,2 / 2,2 / 3), 4(3 / 2$, 3/3), $5(3 /+$, progressive massive fibrosis).
$P>0 \cdot 1)$. In miners without the classic ILO evidence for CWP the release of TNF- $a$ was not related to HRCT score, except for release of TNF- $a$ stimulated with high concentration of endotoxin $(1000 \mathrm{ng} / \mathrm{ml})$. Interestingly, this increased with increasing number of lesions (Spearman, $r=0.35, P<$ $0 \cdot 05, \mathrm{n}=33$ ).

\section{LONGITUDINAL DATA ANALYSIS: RESULTS OF} FIVE-YEAR FOLLOW UP

\section{Follow up characteristics}

Ultimately 104 coal miners (67\% of the original cohort) participated in our follow up (fig 1) and 40 out of 66 coal miners involved in the TNF- $a$ study ${ }^{12}$ attended for our follow up measurements. No selection bias was found for age, smoking, or time underground as was found in the original study (table 3 ). Both groups did not differ for medication (yes/no, two tailed test), or for pneumoconiotic stage (1987 chest radiograph, two tailed test), or for mean release of TNF- $a$ (table 3 ). During the follow up all miners had left active mining, and there had been no occupational exposure for at least four years in half of our miners and for at least two years in more than $85 \%$ of our miners. No selective loss to follow up from active mining had taken place (table 3 ). The mean (SD) age of retirement in our total follow up group $(n=104)$ was $44 \cdot 7(5 \cdot 1)$. Despite retirement a significant proportion of the cohort $(n=104)$ showed progression of CWP. Based on the paired readings of the chest radiographs, it was shown that during this five year follow up period four out of 80 healthy coal miners contracted CWP (5\%), and that in 11 cases existing CWP progressed $(46 \%)$. In two miners progressive massive fibrosis was established ( $3 / 2 \mathrm{rA}$ and $2 / 3 \mathrm{rA}$ ). From the miners of the original TNF- $a$ study who were involved in the follow up study ( $n=$ 40), one out of 30 control miners developed new CWP, and five out of 10 miners had progression of already existing CWP.

Table 3 Group characteristics of the miners involved in the TNF-a study of $1987(n=66)$ and the subgroup involved in the follow up $(n=40)$

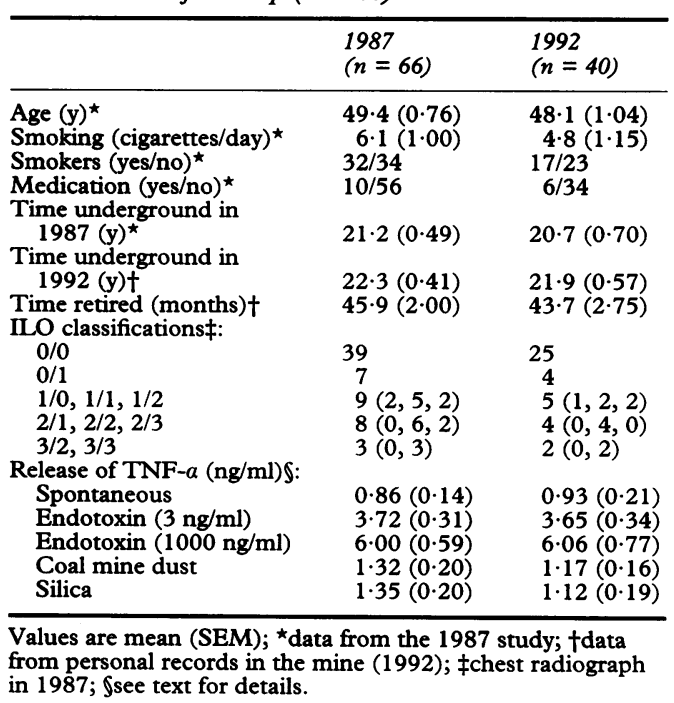

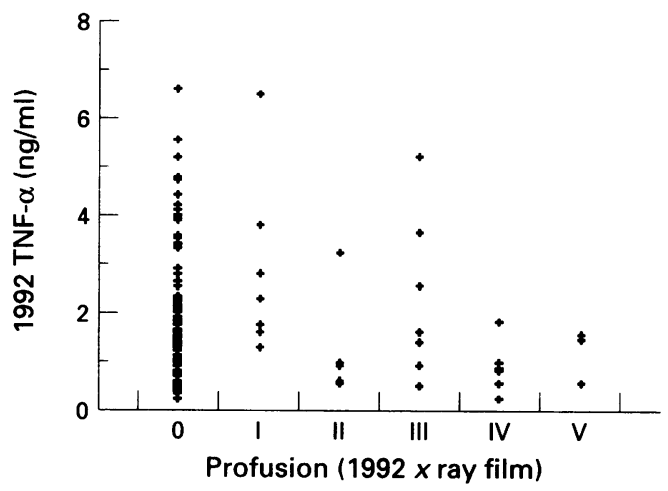


Longitudinal analysis of TNF- $a$ in the follow up group

In the TNF- $\alpha$ follow up group, paired tests of the individual data of 1987 and 1992 ( $n=$ 40), showed significant differences in spontaneous release of TNF- $a$, release of TNF- $a$ upon stimulation with a low concentration of endotoxin and with coal dust $(P<0.05)$. Significant correlations between the TNF- $a$ data of 1987 and 1992 were found upon stimulation with coal mine dust $(r=0 \cdot 44$, $\mathrm{P}<0.01)$ or a low dose of endotoxin $(r=0.35, P<0.05)$. These correlations were also significant in the miners without CWP ( $\mathrm{n}=28, \mathrm{P}<0.01, r=0.49)$, and in all subjects (control miners and miners with CWP) without progression during the five year follow up ( $\mathrm{n}=33, \mathrm{P}<0.05, r=0.43$ ) for stimulated release of TNF- $a$ with coal dust as well as with $3 \mathrm{ng} / \mathrm{ml}$ endotoxin (data not shown). Upon stimulation with $1000 \mathrm{ng} / \mathrm{ml}$ endotoxin no significant correlation was found in the whole TNF- $a$ follow up group, but interestingly, a significant relation was found only in the six miners with five year progression of CWP $(n=6, P<0.05, r=0.89)$. Correlations in the spontaneous release of TNF- $a$ or the release upon stimulation with silica were not found in any subgroup.

\section{TNF- $a$ exposure, and progression}

Multiple linear regression showed that TNF- $a$ is not a marker of exposure as release of TNF- $\alpha$ in either 1992 or 1987 was not related to individual cumulative (dust or quartz) exposure or to any of the other exposure variables in TNF- $a$ follow up subgroup $(n=40)$. Retrospective analysis showed, however, that the cumulative exposure was significantly related to progression of CWP. The OR of cumulative exposure $v$ progression of CWP

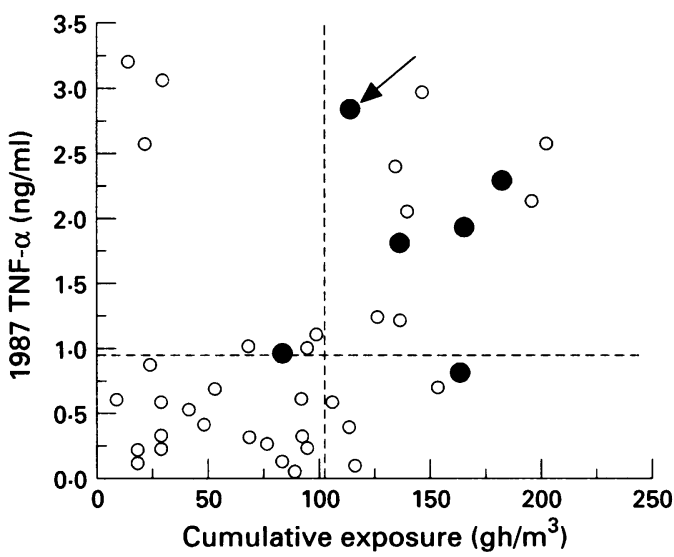

Figure 4 Graphical illustration of the relative risk for miners with high ( $>$ mean $+2 S D s$ ) release of $T N F-a$ (1987) and high ( $>$ mean) cumulative exposure to dust in the progression of CWP compared with all miners involved in the TNF-a follow up study $(n=40)$. Note that no correlation is present between TNF- $a$ and exposure $\left(r^{2}=\right.$ $0.069)$ and that the solid circles, which indicate the people with progression $(n=6)$, are in the right quadrants (high TNF-a and high exposure) of the scheme. The arrow indicates when the subject was first diagnosed to have developed CWP. In the upper right quadrant, age, smoking habits, cumulative exposure and 1987 or 1992 $T N F-a$ release were not different between the miners with progression of CWP $(n=4)$ and those without progression $(n=7)$

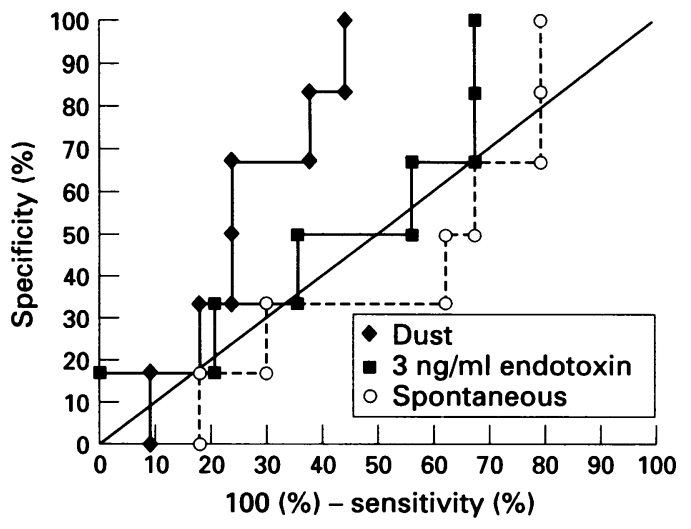

Figure 5 Receiver operator characteristic (ROC) curves of monocyte TNF-a release in 1987 as an indicator of progression of CWP. The diagonal with an area under the curve (AUC) of $50 \%$, marks the theoretical relation of an indicator without discriminative power. $A$ perfect $R O C$ association would be an inverse $L$-shaped curve in the upper left corner of the figure, corresponding to an AUC of $100 \%$. The area under the curve was $44 \%$ for spontaneous release of TNF-a, 55\% for release of TNF-a upon stimulation with $3 \mathrm{ng} / \mathrm{ml}$ endotoxin, and $74 \%$ for release of TNF-a upon stimulation with coal dust.

was $3 \cdot 72$ (significant at a $90 \% \mathrm{CI}$ ), with the mean cumulative exposure $\left(100 \mathrm{gh} / \mathrm{m}^{3}\right)$ as a cut off for high and low exposure. In the TNF- $a$ follow up subgroup $(n=40)$, cumulative exposure was also significantly related to progression at various cut off levels. Figure 4 shows both these observations and that all but one miner who showed progression (or development) of pneumoconiosis between 1987 and 1992 originally had a release of TNF- $a$ that exceeded the normal range in 1987. The relative risk of progression in CWP for miners who showed abnormal in vitro release of TNF- $a$ was $8 \cdot 1(90 \%$ CI $1 \cdot 2-55 \cdot 0)$, with the cut off for dust stimulated TNF- $a$ of 2 SDs above the mean of controls not exposed to dust. To determine sensitivity and specificity at any cut off point of TNF- $a$ upon the different in vitro stimuli, ROC curves were calculated. $^{22}$ Figure 5 shows ROC curves for spontaneous release of TNF- $a$ and for release of TNF- $a$ upon stimulation with $3 \mathrm{ng} / \mathrm{ml}$ endotoxin and coal dust. The strongest association between high TNF- $a$ and progression was found for release of TNF- $a$ stimulated by dust, with an area under the curve (AUC) of $74 \%$. No clear associations were found in all other options $(44 \%<$ AUC $<55 \%)$.

\section{Discussion}

The findings of our follow up study among retired coal workers lend support for an essential role of TNF- $a$ in the genesis of pulmonary fibrosis induced by mineral dusts in general, ${ }^{1581415}$ and CWP in particular. ${ }^{12} 162324$ Moreover this study shows that, when carefully applied, release of monocyte TNF- $a$ is a valid tool for the prognosis of CWP. The large variation of TNF- $a$ found in healthy miners $(0 / 0)$ and miners in the early stages of CWP $(0 / 1)$ proved to be a scientific basis for a susceptibility marker: those with a high release of TNF- $a$ upon stimulation with coal dust are at 
higher risk of developing or progression of CWP. Although to test this hypothesis only analysis of the relation of the original TNF- $a$ concentrations with prospective changes in CWP was needed: TNF- $a$ was also measured in the present study and several other aspects were included. This also allowed us to test the possible feedback mechanisms in the progression of CWP, as already suggested, the reproducibility of the assay and cross sectional results, and effects of the end of occupational exposure (retirement). Individual exposure assessment and HRCT screening, both mainly focused on miners with normal chest radiographs, were included to investigate (or exclude) the role of in vitro stimulated release of TNF- $a$ as a marker of exposure or as a marker of early (fibrotic) effects.

Cross sectional findings in the present study were similar to those of the original study. ${ }^{1}$ Although significant differences in absolute TNF- $a$ concentrations were found, release of TNF- $a$ upon stimulation with coal dust and the low concentration of endotoxin in 1987 and 1992 were significantly correlated. This relation was present in the entire follow up group, as well as in all subjects without progression of CWP. Interestingly, TNF- $a$ concentrations were not correlated in miners with progression of CWP, except for TNF- $a$ released upon stimulation with a high concentration of endotoxin $(n=6)$. This suggests a feedback on release of TNF- $a$ during active fibrosis. In contrast with our previous observations, no significant differences in TNF- $a$ were found between miners with and miners without CWP, and the spontaneous release of TNF- $a$ was significantly higher in the nonexposed controls. Both changes are likely to be due to the retirement of the miners in our present study - that is, a reduced in vivo stimulation or priming. This is supported by the results of Lasalle et al in active and retired miners. These authors found that baseline release of TNF- $\alpha$ in alveolar macrophages was significantly higher in active miners. ${ }^{16} \mathrm{We}$ therefore suggest that serum concentrations of TNF- $a$ and baseline (spontaneous) release from monocytes or alveolar macrophages reflect an acute response to inhaled dusts, whereas the in vitro release by monocytes in peripheral blood shows the chronic adaptation of a subject. In our study such an adaptation may be due both to long term (and subsequent end of) exposure to coal dust and the effect of early pathogenic processes. Evidence for the involvement of exposure is the large variation in release of monocyte TNF- $a$ in miners $v$ controls. The role of early disease also seems evident, considering that the highest release of TNF- $\alpha$ was found in miners in the early stages of CWP.

Although release of TNF- $a$ was highest in the early stages of CWP according to chest radiographs, HRCT analysis showed that release of TNF- $\alpha$ by men within this category was not related to the number of lesions found by HRCT. Therefore, the variation in in vitro release of TNF- $a$, the basis of evaluation of this biomarker, is unlikely to be biased by early fibrotic processes. Also all evidence that could show that TNF- $a$ is an exposure marker is negative; no relation between release of TNF- $\alpha$ and any exposure index (cumulative exposure, exposure years, time since first exposure) could be shown. This does not mean, however, that TNF- $a$ is not affected by exposure, as TNF- $a$ concentrations in coal miners are clearly different from those in subjects without chronic exposure to mineral dust. Perkins et al reported similar findings in subjects with long term exposure to asbestos without evidence of asbestosis. ${ }^{5}$ The lack of relations between release of TNF- $a$ and exposure indices could be considered a false negative result because of the original selection of subjects in the first case-control design, matched for age and years underground, ${ }^{12}$ or to errors in the estimation of individual exposure. One could suggest that differences in exposure are therefore too small to detect any significant correlation with other variables. This is, however, contradicted by the large variation of cumulative exposure (four fold) at the same period of years underground, and the biological plausibility of the existing relations between exposure and CWP: calculated cumulative exposure to dust correlated significantly with pneumoconiotic stage $(r=0.34, \mathrm{P}<0.001$ chest radiographs; $\quad r=0.44, \quad \mathrm{P}<0.005$ HRCT), and was significantly higher in miners with progression of CWP.

Interestingly, the incidence of CWP and progression to more severe stages in this small cohort was significant, especially when taking into account that all miners retired early during follow up. As progression was derived from paired readings of chest radiographs, no doubt exists on the identity of progressed cases. The extent of progression is subject to variation due to differences in size of some radiographs, increased weight of most subjects, and interpretation error. Our findings are in line with epidemiological data that showed that progression is highest in advanced stages of CWP ${ }^{25}$ and that incidence of CWP is more frequent among men who have left the industry than among those in the active work force. ${ }^{26} 27$ Therefore, there are extensive populations at risk of CWP throughout the world and methods of screening and surveillance by careful monitoring of the health of these miners and ex-miners are needed. In our study, both cumulative dust exposure and release of TNF- $a$ in 1987 were significantly related to five year changes in CWP. The (retrospective) estimate of the OR for cumulative exposure was $3 \cdot 72$, and the relative risk for progression of CWP for someone with an abnormal ( $>$ mean $+2 S D$ ) release of TNF- $a$ was $8 \cdot 1$ in this cohort. There is a subtle difference between cumulative exposure and release of TNF- $a$ : dust exposure determines the prevalence of CWP after several years, whereas release of TNF- $a$ determines the individual risk at a certain exposure (fig 4).

It should be emphasised that in vitro release of TNF- $a$ induced by coal mine dust 
was the best predictor of progression, whereas baseline release of TNF- $a$ was not related to five year progression of CWP (fig 4). Again this raises the question of priming of the monocytes by external exposure to mineral dust. Apart from our original suggestion of this phenomenon in coal miners, ${ }^{12}$ priming of macrophages was reported by Mohr et al in rats exposed to silica ${ }^{8}$ and in asbestos workers. ${ }^{5}$ Local lung modulatory factors have been suggested in the upregulation of secretion of TNF- $\alpha$ by monocytes ${ }^{28}$ but also autocrine pathways may be involved in the priming of macrophages. ${ }^{29} 30 \mathrm{We}$ think that priming of monocytes in coal miners reflects the response to chronic release of factors from the lung loaded with coal dust. Studies with alveolar monocytes, and lung tissue of coal miners ${ }^{1624}$ confirmed this hypothesis and also suggested that as well as silica other compounds in coal dust and smoking ${ }^{16331}$ are important in the release of such factors. For example, in our study stimulated release of TNF- $a$ was lower in miners who smoked, whereas the baseline response tended to be higher in non-smokers. Several results suggested the presence of feedback mechanisms that counteract the processes (dust exposure, smoking, and inflammatory response) that upregulate release of TNF- $\alpha$ from monocytes. Previously, and at follow up, we noted a downward trend of stimulated release of TNF- $a$ as CWP stage increased. Moreover, in 1992 release of TNF$a$ was not such a good predictor of progression of CWP as it was in 1987. Also correlations between assays in 1987 and 1992 were only significant in miners without progression of CWP and not in miners whose disease had progressed. We could not test the possible effect of feedback on TNF- $a$ as a marker of progression of CWP in our cohort because only retired miners were involved. Therefore, we are not able to discriminate between the effects of stopping exposure and failure of feedback as determinants of monocyte release of TNF- $a$. This remains an interesting subject for future investigations in a larger cohort of active miners.

In conclusion, our data add in vivo human evidence to the already existing in vitro and animal data that TNF- $a$ is a crucial mediator in lung disease induced by mineral dust. It is appreciated that the size, original selection, and follow up interval of our cohort could limit the significance of our findings. The original study had a case-control design matched for age and exposure to investigate the involvement of TNF- $a$ in CWP. To reach an acceptable response and statistical power (cases with progression), the cohort had to be supplemented with other miners, screened by us for different purposes in the same year. Nevertheless, the reproducibility of cross sectional findings was excellent. Moreover, we showed that TNF- $a$ data are not biased by either exposure or stage of disease and showed a high relative risk of high release of TNF- $\alpha$ at equal exposures and radiological outcomes. Its specificity as a marker is shown by the fact that none of the subjects with a normal release of TNF- $a$ showed progression of disease. Determination of the ROCs (fig 5) showed that the significance of our findings was not solely due to the specific choice of the cut off in the present study, and allowed this marker to be applied to other cohorts of (retired) coal miners. Future follow up will increase the number of cases as the average age of our cohort is well below the current average to contract CWP ${ }^{26}{ }^{27}$ and can help to get a more reliable estimate of the relative risk. Other estimates can come from studies that will use this method as a tool for health surveillance in, for example, miners who leave the active work force.

We are indebted to all coal miners and the Kempense Steenkoolmijnen NV for their cooperation in this study. We thank Luc Lenaerts (MD), Luc Mariën (MD) and Marc van Sprundel (MD, PhD) for reading the chest radiographs, Rob Lamers (MD) for HRCT analysis, Bernard Préat for cumulative exposure estimations, and Thim Derhaag for technical assistance. Finally, we acknowledge Wim Buurman ( $\mathrm{PhD}$ ) for providing the TNF- $a$ assay and useful advice. This study is Supported by grant No 7263

1 Elias JA, Freundlich B, Kern JA, Rosenbloom J. Cytokine networks in the regulation of inflammation and fibrosis in the lung. Chest 1990;97:1439-45.

2 Crystal, RG, Ferrans VJ, Basset F. Biologic basis of pulmonary fibrosis. In: Crystal RG, West JB, Barnes PJ, Cherniack NS, Weibel ER, eds. The lung. Scientific foundations, 1st ed. New York: Raven Press, 1991:2031-46.

3 Snyder GL. Interstitial lung disease: pathogenesis, pathophysiology, and clinical presentation. In: Schwartz MI, King Jr TE, eds. Interstitial lung disease, 1st ed. Toronto BC Decker, 1988:1-4.

4 Brody AR. Asbestos-induced lung disease. Environ Health Perspect 1993;100:21-30.

5 Perkins RC, Scheule RK, Hamilton R, Freidman G, Holian A. Human alveolar macrophage cytokine release in response to in vitro and in vivo asbestos exposure. Exp Lung Res 1993;19:55-65.

6 Piguet PF, Collart MA, Grau GE, Sappino A-P, Vassalli P. Requirement of tumour necrosis factor for development of silica-induced pulmonary fibrosis. Nature 1990; 344:245-7.

7 Driscoll KE, Lindenschmidt RC, Maurer JK, Higgins JM, Ridder G. Pulmonary response to silica or titaniumdioxide: Inflammatory cells, alveolar macrophagedioxide: Inflammatory cells, alveolar macrophagederived cytokines, and hist

8 Mohr C, Gemsa D, Graebner C, Hemenway DR, Leslie KO, Absher PM, Davis GS. Systemic macrophage stimulation in rats with silicosis: enhanced release of tumor necrosis factor- $a$ from alveolar and peritoneal macrophages. Am 7 Respir Cell Mol Biol 1991;5:395-402.

9 Driscoll KE, Hassenbein DG, Carter J, Poynter J, Asquith TN, Grant RA, et al. Macrophage inflammatory proteins 1 and 2: expression by rat alveolar macrophages, fibroblasts, and epithelial cells in rat lung after mineral dust exposure. Am $₹$ Respir Cell Mol Biol 1993;8:311-18.

10 Janssen YMW, Engelen JJ, Giancola MS, Low RB, Vacek P, Borm PJA. Serum type III procollagen N-terminal Peptide in coal miners. Exp Lung Res 1992;19:1-8.

11 Engelen JM, Borm PJA, Sprundel van M, Lenaerts L Blood anti-oxidant parameters in coal workers' pneumoconiosis at different stages. Environ Health Perspect 1990; 84:165-72.

12 Borm PJA, Palmen N, Engelen JM, Buurman WA. Spontaneous and stimulated release of tumor necrosis factor-alpha (TNF) from blood monocytes of miners with coal workers' pneumoconiosis. Am Rev Respir Dis 1988;138: 1589-94.

13 Phan SM, Kunkel SL. Lung cytokine production in bleomycin-induced pulmonary fibrosis. Exp Lung Res 1992;18:29-43.

14 Warren JS, Kunkel ST, Cunningham TW, Johnson KJ, Ward PA. Macrophage-derived cytokines amplify immune complex-triggered $\mathrm{O}_{2}^{-}$. responses by rat alveolar macrophages. Am $\mathcal{F}$ Pathol 1988;130:489-95.

15 Everson MP, Chandler DB. Changes in distribution, morphology, and tumor necrosis factor- $a$ secretion of alveolar phology, and tumor necrosis factor- $a$ secretion of alveolar macrophage subpopulations during the development of 1992:140:503-12.

16 Lasalle $P$, Gosset $P$, Aerts C, Fournier E, Lafitte JE, Degreef JM, et al. Abnormal secretion of interleukin-1 
and tumor necrosis factor- $a$ by alveolar macrophages in coal workers' pneumoconiosis: comparison between simple pneumoconiosis and progressive massive fibrosis. simple pneumoconiosis and p

17 International Labour Organisation. Guidelines for the use of ILO international classification of radiographs of pneumoco nioses. Geneva: International Labour Office, 1980 (Occupational Safety and Health Series No 22 revised)

18 Debets JMH, van der Linden CJ, Spronken IEM, Buurman WA. T-cells mediated production of TNFalpha by monocytes. Scand $f$ Immunol 1988;27:601-9.

19 Lamers RJS, Schins RPF, Wouters EFM, van Engelshoven JMA. Computed tomography of the lungs in coal workers with a normal chest radiograph. Exp Lung Res 1994;21:411-9.

20 Rémi-Jardin M, Degreef JM, Beuscart R, Voisin C, Rémi $\mathrm{J}$. Coal worker's pneumoconiosis: CT assessment in exposed workers and correlation with radiographic findings. Radiology 1990;177:363-71.

21 Hanley JA, McNeil BJ. The meaning and use of the area under a receiver operating characteristic (ROC) curve. under a receiver operating

22 van der Schouw YT, Segers MFG, Smits L, Thoma CMG, Verbeek ALM, Wobbes Th. Towards a more standardized assessment of diagnostic tumour markers. Int $\mathcal{F}$ Oncol 1993;3:979-85.

23 Gosset P, Lasalle P, Vanhée D, Wallaert B, Aerts C, Voisin C, Tonnel AB. Production of tumour necrosis factor- $a$ and interleukin- 6 by human alveolar macrophages exposed in vitro to coalmine dust. Am $\mathcal{f}$ Respir Cell Mol Biol 1991;5:431-6.

24 Vanhée D, Gosset $\mathrm{P}$, Marquette $\mathrm{CH}$, Wallaert B, Lafitte $\mathrm{JJ}$, Gosselin B, et al. Secretion and mRNA expression of
TNF- $a$ and II- 6 in the lung of pneumoconiotic patients. Am 7 Respir Dis 1993;147:A906.

25 Attfield $M$, Wagner $G$. Respiratory disease in coal miners. In: Rom WN, ed. Environmental and occupational medicine, 2nd ed Boston: Little, Brown 1992:325-44.

26 Soutar C, MacLaren W, Annis R, Melville A. Quantitative relations between exposure to respirable coal mine dust and coalworkers' simple pneumoconiosis in men who have worked as miners but have left the coal industry. Brf Ind Med 1986;43:29-36.

27 Mahieu B. L'évolution de la pneumoconiose en France au cours des 20 demières années (Corrigendum expose). Hygien industrial dans les mines. Brussels: Commission des Communautes Européennes Direction Générale Emploi, Relations Industrielles et Affaires Sociales; Direction Santé et Sécurité V/E/4, 1990.

28 Pantelidis P, Southcott AM, Du Bois RM. A comparison of single cell TNF- $a$ secretion in blood and lung of single cell TNF-a secretion in blood and lung Respir Dis 1993;147:A756.

29 Gordon Tanner W, Burress Welborn M, Sheperd VL. Tumor necrosis factor- $a$ and interleukin-1a synergistically enhance phorbol myristate acetate-induced superoxide production by rat bone marrow-derived macrophages. Am ₹ Respir Cell Mol Biol 1992; 7:379-84.

30 Pfeffer KD, Huecksteadt TP, Hoidal JR. Expression and regulation of tumor necrosis factor in macrophages from cystic fibrosis patients. Am $¥$ Respir Cell Mol Biol 1993;9:511-19.

31 Dubar V, Gosset P, Aerts C, Voisin C, Wallaert B, Tonnel $A B$. In vitro acute effects of tobacco smoke on tumour AB. In lar macrophages. Exp Lung Res 1993;19:345-59.

\section{Vancouver style}

All manuscripts submitted to Occup Environ Med should conform to the uniform requirements for manuscripts submitted to biomedical journals (known as the Vancouver style.)

Occup Environ Med, together with many other international biomedical journals, has agreed to accept articles prepared in accordance with the Vancouver style. The style (described in full in the $B M F, 24$ February $1979, \mathrm{p} \mathrm{532}$ ) is intended to standardise requirements for authors.

References should be numbered consecutively in the order in which they are first mentioned in the text by Arabic numerals above the line on each occasion the reference is cited (Manson ${ }^{1}$ confirmed other reports $^{2-5}$... .). In future references to papers submitted to Occup Environ Med should include: the names of all authors if there are seven or less or, if there are more, the first six followed by et al; the title of journal articles or book chapters; the titles of journals abbreviated according to the style of Index Medicus; and the first and final page numbers of the article or chapter. Titles not in Index Medicus should be given in full.

Examples of common forms of references are:

1 International Steering Committee of Medical Editors, Uniform requirements for manuscripts submitted to biomedical journals. Br Med Y 1979;1:532-5.

2 Soter NA, Wasserman SI, Austen KF. Cold urticaria: release into the circulation of histamine and eosinophil chemotactic factor of anaphylaxis during cold challenge. N Engl $\Im$ Med 1976;294:687-90.

3 Weinstein L, Swartz MN. Pathogenic properties of nvading micro-organisms. In: Sodeman WA Jr, Sodeman WA, eds. Pathologic physiology, mechanisms of disease. Philadelphia: W B Saunders, 1974:457-72. 